\title{
Model Desain Penyelenggaraan Pendidikan Inklusif
}

\author{
Agus Hadi Utama \\ Program Studi Teknologi Pendidikan, Fakultas Keguruan dan Ilmu Pendidikan, \\ Universitas Lambung Mangkurat, Banjarmasin \\ E-mail: agus.utama@ulm.ac.id
}

Riwayat artikel: submit: 29 Juli 2021; revisi: 20 Agustus 2021, diterima: 28 September 2021

\begin{abstract}
ABSTRAK
Penyelenggaraan pendidikan inklusif di Indonesia, contohnya di Kota Banjarmasin belum berjalan maksimal, karena beberapa persyaratan standar penyelenggaraan pendidikan inklusif tidak dipenuhi. Oleh sebab itu, pengembangan model desain penyelenggaraan pendidikan inklusif menjadi lebih penting agar bisa digunakan secara seragam untuk melihat keberhasilan implementasi pendidikan inklusif di Indonesia. Model desain penyelenggaraan pendidikan inklusif terdiri dari 6 standar, yaitu: sistem rekrutment $A B K$, sistem rekrutment GPK, modifikasi kurikulum dan evaluasi pembelajarannya, aksesbilitas dan sarana-prasarananya, pendanaan/pembiyaan, dan peran komite sekolah. Penelitian ini termasuk kedalam jenis penelitian dan pengembangan (R\&D) untuk menciptakan suatu model desain penyelenggaraan pendidikan inklusif yang sesuai dengan tujuan pendidikan nasional dan amanah konstitusi Undang-Undang Republik Indonesia No. 20 Tahun 2003 tentang Sistem Pendidikan Nasional. Model desain penyelenggaraan pendidikan inklusif yang terdiri dari 6 standar ini nantinya dapat menjadi bahan rekomendasi kepada sekolah dan komite sekolah dalam menyiapkan prosedur standar operasional (SOP).
\end{abstract}

Kata kunci: Penyelenggaraan Pendidikan Inkusif, Model Penyelenggaraan Pendidikan Inklusif

\section{ABSTRACT}

The implementation of inclusive education in Indonesia, for example in the city of Banjarmasin, has not run optimally, because several standard requirements for the implementation of inclusive education have not been met. Therefore, the development of a design model for the implementation of inclusive education is more important so that it can be used uniformly to see the success of the implementation of inclusive education in Indonesia. The design model for implementing inclusive education consists of six standards, namely: student's recruitment system, teacher's recruitment system, curriculum modification, and learning evaluation, accessibility and infrastructure, funding/financing, and the role of school committees. This research belongs to the type of research and development to create a design model for the implementation of inclusive education following the goals of national education and the constitutional mandate of Law of the Republic of Indonesia No. 20 of 2003 concerning the National Education System. The design model for inclusive education, which consists of six standards, can later be used as recommendations for schools and school committees in preparing standard operating procedures.

Keywords: Inclusive Education Implementation, Inclusive Education Implementation Model 
Utama, A.H. (2021). Model Desain Penyelenggaraan Pendidikan Inklusif. Edudikara: Jurnal Pendidikan dan Pembelajaran, 6(3), 140-151.

\section{PENDAHULUAN}

Pendidikan untuk anak berkebutuhan khusus telah dicantumkan dalam UndangUndang Republik Indonesia Nomor 20 Tahun 2003 tentang Sistem Pendidikan Nasional. Kebijakan tersebut memberi warna baru bagi anak berkebutuhan khusus. Ditegaskan dalam pasal 5 tentang pendidikan khusus di sebutkan bahwa pendidikan khusus merupakan pendidikan untuk peserta didik berkelainan atau peserta didik yang memiliki kecerdasan luar biasa yang diselenggarakan secara inklusi atau berupa satuan pendidikan khusus pada tingkat pendidikan dasar dan menengah. Pasal inilah yang memungkinkan terobosan dan inovasi dalam pelayanan pendidikan bagi anak berkebutuhan khusus berupa penyelenggaraan pendidikan inklusif. Secara lebih operasional, hal tersebut diperkuat dengan Peraturan Menteri Pendidikan Nasional Republik Indonesia Nomor 70 tahun 2009 tentang pendidikan inklusif bagi peserta didik yang memiliki kelainan (Direktorat Pembinaan SLB, 2009).

Sebagaimana diketahui bahwa masih banyak anak-anak Indonesia yang sampai sekarang ini tidak dapat menikmati suasana belajar di bangku sekolah. Tidak sedikit pula anakanak putus sekolah bahkan tidak sekolah sama sekali karena alasan ekonomi yang kemudian diperparah lagi dengan mahalnya biaya pendidikan sekarang ini. Disini peran pendidikan inklusif dibutuhkan sebagai pelindung terhadap hak-hak dasar anak untuk mendapatkan layanan pendidikan secara merata. Seperti dalam penjelasan Undang-undang Nomor 20 tahun 2003 tentang Sistem Pendidikan Nasional Pasal 3 menyatakan bahwa: "Pendidikan nasional berfungsi mengembangkan kemampuan dan membentuk watak serta peradaban bangsa yang bermartabat dalam rangka mencerdaskan kehidupan bangsa, bertujuan untuk mengembangkan potensi peserta didik agar menjadi manusia yang beriman dan bertaqwa kepada Tuhan Yang Maha Esa, berakhlak mulia, sehat, berilmu, cakap, kreatif, mandiri, dan menjadi warga negara yang demokratis serta bertanggung jawab" (Dinas Pendidikan Provinsi Jawa Barat, 2004).

Pendidikan inklusif merupakan proses yang dinamis, agar pendidikan inklusif terus hidup, diperlukan adanya monitoring partisipatori yang berkesinambungan, melibatkan semua stakeholder dalam refleksi diri yang kritis. Satu prinsip inti dari pendidikan inklusif adalah harus tanggap terhadap keberagaman secara fleksibel, senantiasa berubah, dan tidak dapat diprediksi. Jadi, pendidikan inklusif harus tetap hidup dan berjalan sesuai dengan amanah konstitusi. Setiap daerah memiliki sumber daya manusia, karakteristik, dan kultur budaya, serta sistem sosial yang sangat mendasar. Jika hal-hal tersebut dapat dijadikan sebagai pertimbangan dalam mengimplementasikan pendidikan inklusif, niscaya implementasi itu akan berjalan sesuai dengan tujuan yang direncanakan. Faktor-faktor inilah yang kurang dipertimbangkan ketika implementasi pendidikan inklusif digulirkan, sehingga menimbulkan masalah-masalah yang paling mendasar dalam pelaksanaan implementasi pendidikan inklusif.

Ideologi dan pendekatan pendidikan inklusif pertama kali muncul dalam dokumen international pada tahun 1994 dalam "The Salamanca Statement". Pernyataan tersebut di uraikan sebagai berikut: Kami, para delegasi Konferensi Dunia tentang Pendidikan Kebutuhan Khusus yang mewakili sembilan puluh dua pemerintah dan dua puluh lima organisasi internasional, yang berkumpul di sini di Salamanca, Spanyol, dari tanggal 7 - 10 Juni 1994, dengan ini menegaskan kembali komitmen kami terhadap Pendidikan bagi Semua, mengakui perlunya dan mendesaknya memberikan pendidikan bagi anak, remaja, dan orang dewasa penyandang kebutuhan pendidikan khusus di dalam sistem pendidikan reguler, dan selanjutnya dengan ini menyetujui Kerangka Aksi mengenai Pendidikan Kebutuhan Khusus, yang semangat ketetapan-ketetapan serta rekomendasi-rekomendasinya diharapkan akan dijadikan pedoman oleh pemerintah-pemerintah serta organisasi-organisasi dunia (Hunt, P. F., 2011).

Pendekatan ini belum sepenuhnya dilaksanakan dan diterapkan di seluruh Indonesia. Namun, kecenderungannya adalah semakin dapat diterima oleh masyarakat luas walaupun 
Utama, A.H. (2021). Model Desain Penyelenggaraan Pendidikan Inklusif. Edudikara: Jurnal Pendidikan dan Pembelajaran, 6(3), 140-151.

masih banyak masalah-masalah yang dihadapi dilapangan, seperti halnya di Kota Banjarmasin, Kalimantan Selatan. Banyak sekolah yang nampak belum tersedia sumber daya manusia, sarana prasana, modifikasi kurikulum, serta model evaluasi yang sesuai dengan kultur budaya masyarakat Banjar, sehingga berdampak pada pelaksanaan yang kurang maksimal.

Pendidikan inklusif adalah sistem penyelenggaraan pendidikan yang memberikan kesempatan kepada semua anak yang memiliki kelainan dan memiliki potensi kecerdasan dan/atau bakat istimewa untuk mengikuti pendidikan atau pembelajaran dalam lingkungan pendidikan secara bersama-sama dengan anak pada umumnya. Hal ini berarti bahwa setiap anak memiliki kesempatan yang sama untuk memperoleh pendidikan sesuai dengan kemampuannya masing-masing. Berdasarkan keberagaman anak berkebutuhan khusus, permasalahan, serta kebutuhan yang harus dipenuhi sekolah sangatlah bervariasi. Sekolah penyelenggara pendidikan inklusi wajib memahami setiap jenis hambatan, ketunaan, dan bentuk pembelajaran anak-anak berkebutuhan khusus itu sendiri. Persyaratan agar proses pendidikan inklusi dapat dilaksanakan Skjorten D. Miriam (2003:50) mengemukakan bahwa proses menuju inklusi itu panjang dan antara lain akan membutuhkan; 1) perubahan hati dan sikap, 2) reorientasi yang berkaitan dengan asesmen, metode pembelajaran, dan manajemen kelas termasuk penyesuaian lingkungan, 3) redefinisi peran guru dan realokasi sumber daya manusia, 4) redefinisi peran SLB yang ada misalnya, dapatkah sekolah-sekolah ini secara bertahap mulai berfungsi sebagai pusat sumber belajar yang ekstensif?, 5) penyediaan bantuan profesional bagi para guru dalam bentuk reorientasi pelatihan dalam jabatan dan penataran guru, kepala sekolah dan guru kelas/guru pendamping khusus sehingga mereka juga akan dapat memberikan kontribusi terhadap proses menuju inklusi dan bersikap fleksibel jika diperlukan, dan 6) pembentukan, peningkatan kemitraan antara guru dan orang tua, demi saling reorientasi dan melakukan peningkatan serta pertukaran pengalaman, bantuan dan nasehat. Inklusi juga akan memerlukan sistem pendidikan yang fleksibel termasuk kurikulum dan sistem ujian yang fleksibel bagi anak berkebutuhan khusus.

Dengan demikian sekolah inklusif bukan sekedar menerima anak berkebutuhan khusus namun lebih dari itu sekolah inklusi harus mampu memberikan layanan pendidikan yang sesuai dengan kebutuhan siswa sehingga mampu menciptakan sistem pembelajaran yang aktif, kreatif dan inovatif bagi semua siswa.

Permasalahan yang ditemui dilapangan, dari beberapa sekolah inklusi di Kota Banjarmasin, masih mengalami kesulitan dalam memahami dan melayani siswa dengan hambatan khusus (Mansur, H., 2013). Pelaksanaan Pendidikan inklusif di kota Banjarmasin belum maksimal tersebut dikarenakan pengetahuan warga sekolah tentang setting Pendidikan inklusif masih rendah, jumlah guru, dan siswa tidak sebanding, serta kondisi fisik sekolah belum memiliki aksesbilitas dan sarana-prasarana pendukung anak berkebutuhan khusus (ABK).

\section{KAJIAN PUSTAKA}

Tantangan pertama dalam menyelenggarakan pendidikan inklusif di sekolah-sekolah regular adalah memberikan pemahaman awal tentang pentingnya penyelenggaran pendidikan inklusif kepada warga sekolah sesuai dengan amanah konstitusi. Pemahaman awal tentang pentingnya pendidikan inklusif dapat dilakukan melalui program pendidikan dan pelatihan (diklat) yang difasilitasi oleh pemerintah provinsi setempat (Salim, A., Mansur, H., \& Utama, A. H., 2020). Tantangan kedua dalam menyelenggarakan pendidikan inklusif adalah menyiapakan tenaga pendidik pendamping khusus yang direkrut oleh pemerintah provinsi setempat dan melibatkan beberapa perguruan tinggi yang memiliki lulusan pendidikan luar biasa (Bari, Safani \& Yasin, Mohd \& Hamzah, Mohd., 2014). Sikap guru terhadap penerapan program inklusif ditinjau dari aspek guru itu sendiri masih sangat minim akan wawasan desain pembelajaran pendidikan inklusif, salah satu faktor penyebabnya adalah kurangnya tenaga pendidik berlatar 
Utama, A.H. (2021). Model Desain Penyelenggaraan Pendidikan Inklusif. Edudikara: Jurnal Pendidikan dan Pembelajaran, 6(3), 140-151.

belakang pendidikan luar biasa untuk menjadi guru pendamping khusus (GPK) di sekolah inklusif (Triwulandari, A., \& Pandia, W. S. S., 2015).

Kemampuan guru pendamping khusus (GPK) dalam mengidentifikasi dan assessment siswa ABK harus berlatar belakang pendidikan luar biasa (Kamariah, Nur \& Mohd, Isa \& Hamzah, et all., 2019). Kemampuan GPK dalam mendampingi siswa ABK dipengaruhi oleh keinginan dan kesadaran akan penanaman pendidikan inklusif (Anthony, Nancy \& Yasin, Mohd., 2019). Pengetahuan dan sikap siswa ABK perlu dilakukan identifikasi awal terlebih dahulu dan assessment dalam tahapan rekrutment (Hasnah, Toran \& Muhamad, Tajul, et all., 2010). Implementasi pendidikan inklusif akan terlaksana dengan baik dan efektif apabila sistem rekrutment-nya sudah dilakuan dengan benar yaitu melalui tahapan identifikasi dan assessment kondisi/karakteristik siswa ABK (Hanafi, Mohd \& Yasin, Mohd \& Jasmy, Mohd, et all., 2019). Tantangan ketiga dalam menyelenggarakan pendidikan inklusif adalah menyiapakan aksesbilitas dan sarana-prasarana bagi ABK (Mansur, H., \& Utama, A. H., 2021). Sarana dan prasarana pendidikan inklusif sudah banyak diimplmentasikan kedalam bentuk digitalisasi atau media pembelajaran berbasis teknologi dan informasi (Mohd Rashid, Syar \& Yasin, Mohd \& Ashaari, Noraidah., 2019). Computer Assisted Teaching and Learning (CAT) untuk anak ABK perlu dikembangkan dalam bentuk software maupun hardware-nya (Mansur, H., Utama, A. H., \& Prastitasari, H., 2021).

Penyelenggaraan pendidikan inklusif dapat dilihat dari aspek persiapan (antecendent), proses (transaction), dan produk (Mansur, Hamsi, Yasin, Mohd \& Liong, K., 2019). Penilaian siswa ABK diselaraskan dengan modifikasi kurikulum program perkembangan individu (PPI), yaitu program pembelajaran individual (Omar, Shokhan \& Yasin, Mohd \& Razak, et all., 2019). Penilaian siswa ABK lebih diutamakan kepada perubahan sikap dan tingkah laku di lingkungan sekitar (Omar, Shokhan \& Radzani, Mohd \& Yasin, et all., 2018). Penilaian siswa ABK dilihat dari aspek pengetahuan dan disesuaikan dengan tahap perkembangan kondisi/karakteristik siswa (Abdulrahman, S.O. \& Razak, M.R.A. \& Yasin, et all., 2018). Pengembangan model modifikasi kurikulum sekolah inklusif berbasis PPI perlu dievaluasi kembali sesuai dengan kondisi/karakteristik individu dan kultur sistem sosial masyarakat Indonesia (Salim, A., \& Utama, A. H., 2020).

\section{METODE}

Penelitian ini termasuk dalam kategori Research and Development (R\&D), Pada aspek researchnya dicari jawaban terhadap pertanyaan penelitian yang sekaligus dikemas dalam rumusan permasalahan tentang menciptakan suatu model desain penyelenggaraan pendidikan inklusif yang sesuai dengan tujuan pendidikan nasional dan amanah konstitusi Undang-Undang Republik Indonesia Nomor 20 Tahun 2003 tentang Sistem Pendidikan Nasional. Berkenaan dengan hal tersebut, dalam pengembangannya ditentukan sebuah model desain pengembangan. Desain penelitian merupakan rencana tentang cara mengumpulkan dan menganalisis data agar dapat dilaksanakan secara ekonomis serta serasi dengan tujuan penelitian (Nazir Moh., 2010). Model yang digunakan untuk mengembangkan model desain penyelenggaraan pendidikan inklusif ialah kombinasi Borg \& Gall (1983) dan Martin Tessmer (1996) sehingga tercipta prosedur pengembangan sebagai berikut: Analysis (Research \& Information Collection), Design (Planing and Prototyping), Development and Formative Evaluation (Experts Review, One to One Evaluation, Small Group Evaluation, and Field Test), dan Implementation (Desimination and Implementation). Untuk selanjutnya desain penelitian tersebut dapat digambarkan pada gambar 1 di bawah ini. 
Utama, A.H. (2021). Model Desain Penyelenggaraan Pendidikan Inklusif. Edudikara: Jurnal Pendidikan dan Pembelajaran, 6(3), 140-151.

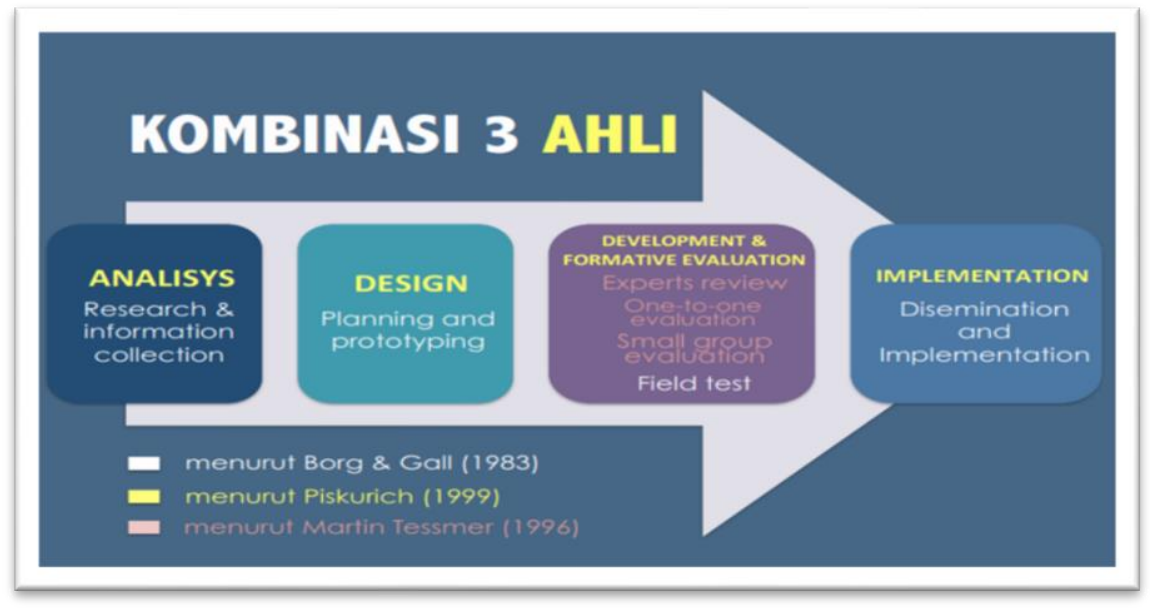

Gambar 1. Model Desain Pengembangan

Teknik pengumpulan data menggunakan metode observasi dan wawancara. Populasi dan sampel diambil dari Provinsi Kalimantan Selatan, khususnya sekolah-sekolah penyelenggara pendidikan inklusif di Kota Banjarmasin, karena sampel yang dipilih memenuhi syarat sebagai perwakilan dari penyelenggra pendidikan inklusif di Indonesia.

Setelah data diperoleh melalui metode wawancara dan observasi terkumpul, maka peneliti melakukan analisis data secra deskriptif dengan cara sebagai berikut:

1. Tahap analisis, yaitu dengan cara mendiskusikan fenomena penelitian dengan perspektif teori, temuan penelitian yang relevan, dan pengalaman peneliti. Hal ini dimaksudkan untuk menemukan kekuatan dan kelemahan dari sekolah-sekolah penyelenggara pendidikan inklusif.

2. Tahap inferensi, yaitu untuk merumuskan prinsip-prinsip dan filosofi sekolah-sekolah penyelenggara pendidikan inklusif berdasarkan analisis kekuatan dan kelemahankelemahan dalam penyelenggaran pendidikan inklusif. Dimaksudkan agar dapat meningkatkan unsur-unsur yang menjadi kekuatan sekolah dalam mencapai tujuan pendidikan yang diharapkan. Adapun analisis data digunakan adalah Analisis data model interaktif Miles, M. B. \& Huberman, A. M., dalam Rohidi, T.R., 1992 akan disajikan sebagai berikut:

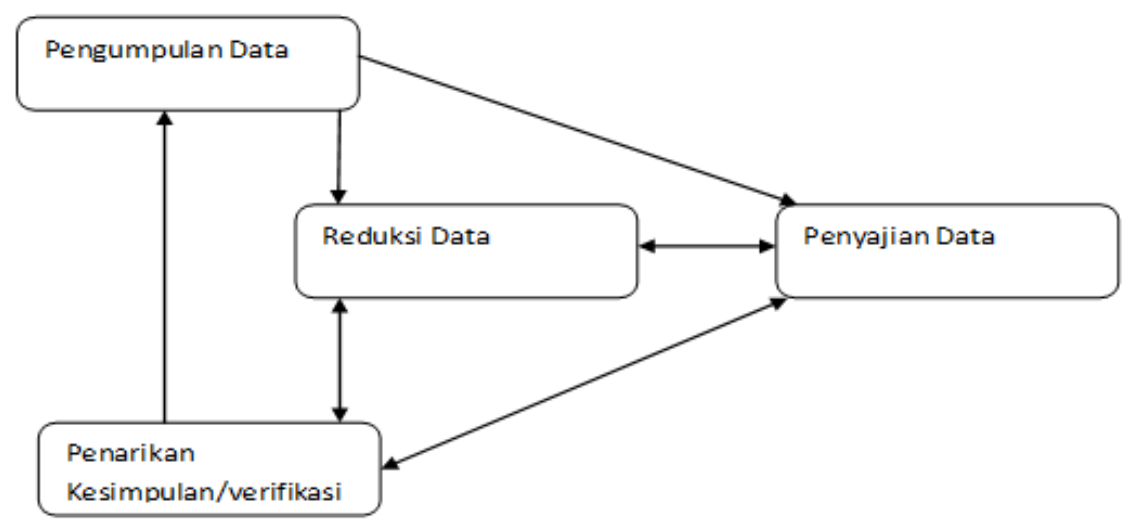

Gambar 2. Analisis Data Model Desain Interaktif 
Utama, A.H. (2021). Model Desain Penyelenggaraan Pendidikan Inklusif. Edudikara: Jurnal Pendidikan dan Pembelajaran, 6(3), 140-151.

\section{HASIL DAN PEMBAHASAN Hasil Penelitian}

Hasil penelitian menunjukkan bahwa penyelenggaran pendidikan inklusif di sekolahsekolah inklusif Kota Banjarmasin adalah sebagai berikut: Pertama, pengetahuan kepala sekolah dan guru tentang pendidikan inklusif masih sangat minim. Kedua, belum terdapatnya Guru Pendamping Khusus (GPK) bagi anak berkebutuhan khusus. Berdasarkan studi pendahuluan tersebut diperoleh informasi bahwa SMPN 14 yang ditunjuk menjadi sekolah inklusif pada awalnya merupakan sekolah umum/reguler yang tidak didesain atau dipersiapkan secara khusus untuk menyelenggarakan program pendidikan inklusif. Pengetahuan guru mengenai konsep pendidikan inklusif maupun pengetahuan tentang anak berkebutuhan khusus masih minim. Sebagian besar guru-guru di sekolah inklusif belum pernah mengikuti pengayaan maupun pelatihan terkait pendidikan inklusif. Baru sekitar 1-2 orang dari masingmasing sekolah yang mendapatkan kesempatan mengikuti pelatihan. Perwakilan guru tersebut diharapkan dapat menularkan pengetahuan yang didapatkan melalui pelatihan maupun seminar dan workshop. Namun, hal tersebut masih belum dapat terwujud dengan optimal. Selain itu, seminar dan workshop yang pernah diberikan hanya menyentuh sisi pedagogis, namun luput melihat sisi psikologis dari kesiapan peserta pelatihan (guru).

Ketiga, perencanaan pembelajaran dilakukan tanpa pertimbangan identifikasi dan asesment. Tidak adanya perencanaan dan asesment tentunya akan berdampak pada penanganan khusus karakteristik/kondisi siswa. Tanpa melakukan asesment, guru tidak akan mengetahui persoalan-persoalan pada diri siswa yang berkebutuhan khusus. Hal demikian tentu saja mereka juga tidak akan dapat memberirikan pelayanan pendidikan inklusif yang optimal. Apalagi anak-anak berkebutuhan khusus mencakup berbagai macam jenis dan derajat kelainan yang bervariasi. Assesment adalah satu-satunya cara bagaimana dan dengan cara apa guru dapat memberikan pelayanan Pendidikan inklusif yang sesuai bagi anak berkebutuhan khusus. Dengan demikian akan lebih mudah tercapai peningkatan kompetensi siswa dalam proses belajarnya.

Keempat, penerimaan anak berkebutuhan khusus (ABK) di sekolah tersebut masih terbilang "tebang pilih". Kelima, ABK belum sepenuhnya terlibat dalam proses pembelajaran. Keenam, sistem pembelajaran yang belum mengakomodir kebutuhan pembelajaran pada ABK. Ketujuh, sistem penilaian pembelajaran yang disamakan antara $A B K$ dan anak pada umumnya. Kedelapan, lingkungan kelas dan sekolah yang belum memiliki standar sarana dan prasarana/aksebilitas bagi ABK. Kesembilan, komite sekolah belum memaksimalkan perannya dalam mendukung pelaksanaan pendidikan inklusif. Kesepuluh, anggaran (dana) sekolah masih minim.

Penyelenggaraan pendidikan inklusif di sekolah-sekolah inklusif Kota Banjarmasin dengan merumuskan aspek kekuatan dan kelemahan sekolah dalam menyelenggarakan pendidikan inklusif. Untuk itu, agar aspek-aspek itu dapat terumuskan maka menggunakan analisis SWOT. Analisis ini didasarkan pada logika yang dapat memaksimalkan kekuatan (Strenghts) dan peluang (Opportunities), namun secara bersamaan dapat meminimalkan kelemahan (Weaknesses) dan ancaman (Threats). Proses pengambilan keputusan strategis selalu berkaitan dengan pengembangan visi, misi, tujuan, dan rencana strategis untuk menghasilkan model desain pembelajaran Pendidikan inklusif yang tepat guna. Selain itu, ketika analisis SWOT digunakan untuk mengukur sekolah, maka dimungkinkan bagi sebuah sekolah untuk mendapatkan sebuah gambaran menyeluruh mengenai situasi sekolah itu dalam hubungannya dengan masyarakat, lembaga-lembaga pendidikan yang lain, dan input-proses-output yang dihasilkan. Sedangkan pemahaman mengenai faktor-faktor eksternal, (terdiri atas ancaman dan kesempatan), yang digabungkan dengan suatu pengujian mengenai kekuatan dan kelemahan akan membantu dalam mengembangkan sebuah visi, misi, tujuan, dan rencana strategis tentang model desain penyelenggaraan pendidikan inklusif yang relevan dan dinamis. 
Utama, A.H. (2021). Model Desain Penyelenggaraan Pendidikan Inklusif. Edudikara: Jurnal Pendidikan dan Pembelajaran, 6(3), 140-151.

Prakiraan seperti ini diterapkan dengan mulai membuat program pendidikan inklusif yang kompeten atau mengganti program-program yang tidak relevan serta berlebihan dengan program yang lebih ringkas, inovatif, dan relevan. Beberapa lingkungan internal-eksternal di sekolah-sekolah penyelenggara pendidikan inklusif:

1. Tenaga pendidik dan kependidikan GPK

2. Kelas/laboratorium, media pembelajaran, aksesbilitas, dan sarana-prasarana (lingkungan belajar)

3. Karakteristik/kondisi siswa ABK yang ada

4. Anggaran dana operasional penyelenggaraan sekolah inklusif

5. Modifikasi kurikulum PPI, kegiatan ekstra, intra, dan Ko-Kurikuler

6. Struktur organisasi dan komite sekolah

7. Beberapa lingkungan eksternal di sekolah-sekolah penyelenggara Pendidikan inklusif:

a. Orang tua dan keluarga siswa

b. Struktur sistem sosial/lingkungan masyarakat

c. Sekolah/lembaga tinggi sebagai persiapan lanjutan

d. Keanekaragaman budaya daerah/kearifan lokal masyarakat Banjar

e. Demografi daerah dan faktor ekonomi

Dari kedua lingkungan tersebut, baik lingkungan internal maupun lingkungan eksternal harus dikelola dengan baik. Jika tidak, maka sesuatu yang semestinya menjadi kekuatan justru nantinya berubah menjadi kelemahan bagi sekolah-sekolah penyelenggara Pendidikan inklusif di Kota Banjarmasin. Kaitannya dengan penelitian ini, adalah lingkungan internal dan eksternal bagi sekolah-sekolah penyelenggara Pendidikan inklusif di Kota Banjarmasin dijadikan potensi penguat dalam penyusunan model desain pembelajaran bagi anak berkebutuhan khusus adalah sebagai berikut: Pertama, lingkungan internal memiliki potensi dapat menjalankan model desain pembelajaran bagi anak berkebutuhan khusus karena komite sekolah, tenaga pendidik, dan tenaga administratif, serta ruang kelas mampu dioptimalkan keberadaannya. Kedua, lingkungan eksternal. Orang tua dan keluarga siswa diajak untuk berpartisipasi dalam penyelenggaraan pendidikan inklusif. Partisipasi dan kontribusi dari orangtua siswa akan terlaksana dengan baik jika beberapa informasi yang berkenaan dengan program sekolah mampu dikomunikasikan dengan baik (Abdulrahman, M., 2003).

\section{Pembahasan}

Pengembangan Model Desain Penyelenggaraan Pendidikan Inklusif adalah merumuskan kembali rencana model desain penyelenggaraan bagi anak berkebuuhan khusus berdasarkan data, teori, dan pengalaman lapangan yang ada, kemudian didiskusikan secara terbatas dengan beberapa tenaga pengajar penyelenggara Pendidikan inklusif di Kota Banjarmasin. Pembahasan rumusan model desain pembelajaran bagi anak berkebutuhan khusus akan disajikan sebagai berikut:

1. Sistem Rekrutment ABK: Data mengenai Rekrutmen siswa berkebutuhan khusus sedikitnya ada 4 temuan. 1) SLTP Negeri 10 dan SLTP Negeri 14 memberikan kuota bagi siswa berkebutuhan khusus setiap tahun ajaran baru. 2) Sekolah telah menyelenggarakan proses identifikasi dan asesment bagi siswa berkebutuhan khusus. 3) Kedua SLTP inklusif di Kota Banjarmasin mewajibkan siswa yang ABK untuk memiliki rekomendasi dari sekolah yang sebelumnya (SD). 4) Kedua SLTP melakukan kerjasama dengan orangtua, meskipun secara khusus terdapat perbedaan kerjasama antara sekolah yang satu dan lainnya. Proses identifikasi/perekrutan dilakukan 1 kali dalam satu tahun ajaran baru. Karena sekolah- 
Utama, A.H. (2021). Model Desain Penyelenggaraan Pendidikan Inklusif. Edudikara: Jurnal Pendidikan dan Pembelajaran, 6(3), 140-151.

sekolah penyelenggara pendidikan inklusif mengalami keterbatasan guru pendamping khusus (GPK) maka disarankan membatasi pendaftar anak berkebutuhan khusus. Minimal 1 dan atau maksimal 2 anak berkebutuhan khusus disetiap kelas dengan klasifikasi anak tersebut sudah dapat mengontrol emosi dan perilaku di dalam kelas bukan berdasarkan kelemahan kemampuan akademiknya. Seleksi dilakukan dengan memberikan kesempatan (kuota) kepada seluruh ABK yang mendaftar dan kelulusan ditentukan oleh tingkat emosi dan sosial anak berkebuthan khusus. Dalam perekrutan ABK sekolah melibatkan tenaga ahli untuk mengukur tingkat emosi dan sosial anak tersebut. ABK yang belum diterima di sekolah kemudian direkomendasikan di sekolah-sekolah inklusif lainnya yang telah menyelenggarakan pendidikan inklusif. Perekrutan ABK dengan melibatkan tenaga ahli dimaksudkan agar sekiolah memiliki data pribadi siswa dengan baik dan akurat. Sekolah yang tidak memiliki data pribadi $A B K$ berdampak pada proses pembelajaran dan/atau pengembangan bakat dan minat $A B K$ itu sendiri. Selain itu, pihak sekolah tidak bisa melakukan promosi atas prestasi atau karya-karya ABK. Dengan demikian, ketersedian data pribadi $A B K$ yang memadai pada setiap perekrutan $A B K$ mengawali kebijakan-kebijakan sekolah inklusif pada ABK.

2. Sistem Rekrutment GPK: Data mengenai rekrutment guru pendamping khusus (GPK) sedikitnya diperoleh 2 data. 1) pada SLTP 10 belum terdapat GPK yang mendampingi siswa berkebutuhan khusus dalam belajar di kelas atau menyususn RPP. 2) di SLTP Negeri 14, GPK terdapat 10 (orang) yang kesemuanya berlatarbelakang PLB. Sedangkan data mengenai Kurikulum juga sama, yaitu ada dua temuan. 1) di SLTP Negeri 10 belum melakukan pengembangan kurikulum bagi siswa berkebutuhan khusus. 2) SLTP Negeri 14 yang didalamnya terdapat GPK melaksanakan pengembangan atau modifikasi kurikulum bagi siswa berkebutuhan khusus. Peran guru pendamping khusus (GPK) sangat diperlukan dalam tercapainya kesuksesan penyelenggaran program pendidikan inklusif. GPK dibantu dengan tenaga ahli melakukan identifikasi awal, assessment akademik, dan asesmen perkembangan mental/sosial peserta didik. GPK yang tergabung dalam komite sekolah juga diberikan pemahaman oleh pihak sekoah untuk mendukung program pendidikan inklusif baik dukungan moral maupun pembiayaan. Upaya untuk memenuhi Ketersedian sumber daya manusia (GPK) adalah dengan mengajukan kerjasama dengan SLB terdekat. Tujuannya adalah untuk membantu melakukan asesment anak berkebutuhan khusus. Selain itu sekolah juga dapat bekerjasama dalam pengadaan alat bantu bagi anak berkebutuhan khusus. SLTP Negeri 14 Banjarmasin juga bekerjasama dengan SMA atau SMK yang telah menyelenggarakan pendidikan inklusif untuk membantu alumni (ABK) dalam melanjutkan pendidikan tinggi (Arum, W.S.A., 2004).

3. Modifikasi Kurikulum dan Evaluasi Pembelajarannya: Data mengenai modifikasi kurikulum di SLTP 14 dan SLTP 10, guru telah menyusun RPP sesuai dengan kriteria ruanglingkup RPP yang peneliti tetapkan berdasarkan pedoman penyelenggaraan pendidikan inklusif. Kedua, di SLTP Negeri 10 meskipun belum ada GPK setiap guru mata pelajaran menyajikan pembelajaran dengan berusaha meningkatkan aktivitas belajar bagi ABK. Ketiga, pada SLTP Negeri 14, guru mata pelajaran bekerjasama dengan GPK. Keempat, di SLTP Negeri 10 tidak terdapat perbedaan penilaian antara siswa ABK dengan siswa pada umumnya. Sedangkan di SMP 14 sudah dibedakan. Perencanaan pembelajaran bagi anak berkebutuhan khusus 
Utama, A.H. (2021). Model Desain Penyelenggaraan Pendidikan Inklusif. Edudikara: Jurnal Pendidikan dan Pembelajaran, 6(3), 140-151.

dimulai melalui asesment akademik dan asesment perkembangan pserta didik. Kegiatan asesment dilakukan oleh tenaga ahli bekerjasama dengan GPK. Hasil dari kegiatan asesment tersebut menjadi rujukan utama dalam merencanakan pembelajaran atau penyesuian kurikulum bagi anak berkebutuhan khusus (Berit H. Johnsen dan Miriam D. Skjorten, 2003). Kurikulum yang digunakan di kelas inklusi adalah kurikulum anak normal (reguler) yang disesuaikan (dimodifikasi sesuai) dengan kemampuan awal dan karakteristik/kondisi siswa ABK. Model pengembangan kurikulum tersebut dinamakan dengan jenis model modifikasi. Komponen kurikulum berupa aspek pembelajaran yang dimodifikasi terletak pada empat komponen utama pembelajaran yaitu silabus, RPP, dan sistem evaluasi. Selanjutnya menentukan penyusunan Program Pembelajaran Individual (PPI). Pengembangan program pendidikan individu tersebut didasarkan pada data pribadi $A B K$ yang dimiliki pihak sekolah saat penerimaan siswa ABK. Maka sangat dimungkinkan bagi sekolah inklusif yang tidak memiliki data pribadi ABK tidak membuat PPI. Tanpa PPI, program yang dilaksankan tidak sesuai dengan bakat dan minat pada ABK. Proses pembelajaran bagi anak berkebutuhan khusus yaitu menempatkan posisi anak sesuai dengan kemampuan sosialnya. Disarankan anak berkebutuhan khusus duduk dibagian pinggir ruang kelas. Guru kelas menjelaskan pembelajaran seperti biasanya, diikuti GPK yang tetap mengontrol situasi anak berkebutuhan khusus. Setelah guru mata pelajaran menjelaskan dan memberikan tugas bagi siswa pada umumnya, selanjutnya GPK membimbing anak berkebutuhan khusus belajar secara individual sesuai dengan PPI yang telah disusun. Jika ABK mampu mengikuti pembelajaran secara klasikal maka GPK tidak perlu untuk membimbing secara individual. Saat proses pembelajaran diharapakan guru kelas selalu menggunakan media audio-visual dibantu oleh GPK untuk membantu ABK dalam memahami materi pembelajaran.

4. Aksesbilitas dan Sarana-Prasarananya: data Sarana dan Prasarana terhimpun sedikitnya ada dua yang dapat disimpulkan. 1) SLTP Negeri 10 di temukan belum terdapat media pembelajaran khusus bagi siswa berkebutuhan khusus. 2) SLTP Negeri 14 menunjukkan bahwa guru pendamping khusus (GPK) menggunakan media belajar khusus. Hal sama juga terdapat pada data pembiayaan yang sedikitnya ada 2 yang dapat disimpulkan. 1) SLTP Negeri 14 Upah yang diperoleh GPK masih kurang dari upah minimum provinsi (UMP). 2) Di SLTP Negeri 10 dan SLTP Negeri 14 bahwa bantuan dana dari pemerintah dalam penyelenggaraan pendidikan inklusif masih sangat minim.

5. Anggaran Dana/Pembiyaan: Data hasil penelitian menunjukkan bahwa upah yang diterima GPK khususnya di SLTP 14 belum sesuai dengan UMP. Maka, pemerintah harus sesegera menentukan dan mengatur kebijakan tentang pengupahan bagi GPK. Hal ini agar tidak bertentangan dengan Undang-undang ketenagakerjaan pasal 88 ayat (4) diamanatkan bahwa pemerintah menetapkan upah minimum berdasarkan Kebutuhan Hidup Layak (KHL) dengan memperhatikan produktivitas dan pertumbuhan ekonomi.

6. Peran Komite Sekolah: Peran serta masyarakat sangat penting diwujudkan dalam implementasi pendidikan kebutuhan khusus, karena masyarakat memiliki berbagai sumberdaya yang dibutuhkan sekolah dan sekaligus masyarakat juga sebagai pemilik sekolah di samping pemerintah. Di SLTP Negeri 10 dan 14 telah melibatkan komite sekolah dalam merencanakan pendidikan inklusif. 
Utama, A.H. (2021). Model Desain Penyelenggaraan Pendidikan Inklusif. Edudikara: Jurnal Pendidikan dan Pembelajaran, 6(3), 140-151.

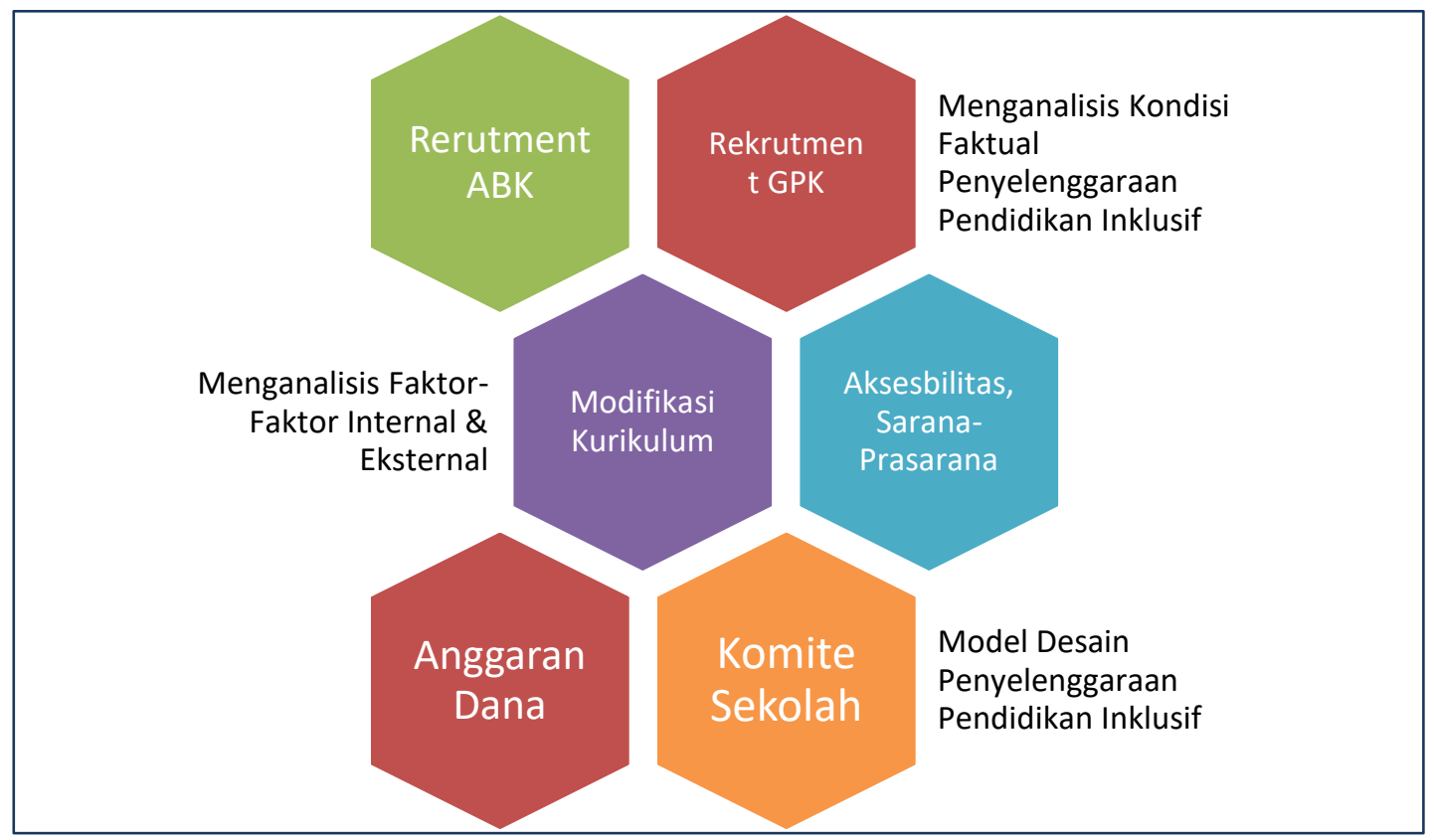

Gambar 1. Model Desain Penyelenggaraan Pendidikan Inklusif

\section{SIMPULAN DAN SARAN}

Model desain penyelenggaraan pendidikan inklusif dapat digunakan sebagai pedoman penyelenggaraan pendidikan inklusif yang sesuai dengan tujuan pendidikan dan amanah konstitusi. Adapun komponen-komponen pelaksanaan model desain tersebut sebagai berikut:

1. Sistem rekrutment ABK

2. Sistem rekrutment GPK

3. Merancang dan Mengembangkan Modifikasi Kurikulum

4. Pengadaan Aksesbilitas, Sarana-Prasarana

5. Ketersediaan Anggaran Dana/Pembiayaan Penyelenggaraan Pendidikan Inklusif

6. Peran Komite Sekolah

Berdasarkan model desain penyelenggaraan pendidikan inklusif yang telah diuraikan, maka direkomendasikan kepada sekolah dan komite sekolah sebagai pelaksana pendidikan inklusif untuk perlu menyiapkan standar operasional prosedur (SOP) sistem rekrutment ABK, perekrutan sumber daya manusia (guru pembimbing khusus), pengadaan sarana-prasarana yang mendukung terlaksananya proses pembelajaran inklusi, memiliki alokasi dana yang memadai agar proses pembelajaran inklusif berjalan dengan efektif. Peran komite sekolah lebih dioptimalkan pada membuat pedoman dan peraturan standar pelaksanaan pendidikan inklusif. Adapun peraturan yang dimaksud tersebut ialah: modifikasi kurikulum, penyusunan program pembelajaran individual (PPI), maupun standar penilaian siswa berkebutuhan khusus. Setelah model penyelenggaraan pendidikan inklusif ini dilaksanakan, perlu adanya penelitian lanjutan terkait evaluasi model penyelenggaraan pendidikan inklusif. 
Utama, A.H. (2021). Model Desain Penyelenggaraan Pendidikan Inklusif. Edudikara: Jurnal Pendidikan dan Pembelajaran, 6(3), 140-151.

\section{REFERENSI}

Abdulrahman, S.O. \& Razak, M.R.A. \& Yasin, Mohd \& Dauwed, Mohammed. (2018). Validity and Reliability Questionnaire for Social, Environment and Self-Efficacy Related of Deaf Adolescents Physical Activity. Journal of Theoretical and Applied Information Technology. 96. 7041-7054.

Anthony, Nancy \& Yasin, Mohd. (2019). Trainee Teachers Level of Willingness for Inclusive Education. Journal of ICSAR. 3. 79-83. 10.17977/um005v3i12019p079.

Arum, W.S.A. (2004). Perspektif Pendidikan Luar Biasa dan Implikasinya Bagi Penyiapan Tenaga Kependidikan. Jakarta: Depdiknas.

Berit H. Johnsen dan Miriam D. Skjorten (2003). Pendidikan Kebutuhan Khusus-Sebuah Pengantar, Program Pendidikan Pasca Sarjana Universitas Pendidikan Indonesia. Bandung.

Borg, W.R. \& Gall, M.D. Gall. (1983). Educational Research: An Introduction, Fifth Edition. New York: Longman.

Departemen Pendidikan Nasional (2003). Kebijakan pemerintah Dalam Pendidikan Inklusi, Jakarta.

Dinas Pendidikan Provinsi Jawa Barat (2004). Petunjuk Pelaksanaan Standard Pelayanan Minimal Bidang Pendidikan di Jawa Barat, Dinas Pendidikan Jabar.

Direktorat Pembinaan SLB, (2009). Pedoman Khusus Penyelenggaraan Pendidikan Inklusif, Jakarta: Dapartemen Pendidikan Nasional.

Hanafi, Mohd \& Yasin, Mohd \& Jasmy, Mohd \& Rahman, Abd \& Tahar, Mohd Mokhtar \& Norfirdhaus, Siti \& Ashaari, Mohammed. (2019). Implementation of Inclusive Education Program in Malaysia \& Indonesia for Hearing Impaired Students. International Journal of Emerging Technologies in Learning (iJET). 7. 16-19.

Hasnah, Toran \& Muhamad, Tajul \& Yasin, Mohd \& Tahar, Mohd Mokhtar \& Hamzah, Nur. (2010). Knowledge and Attitude of Peers Towards Students with Disabilities in Malaysian Public Institute of Higher Education. ASEAN Journal of Teaching \& Learning in Higher Education.

Hunt, P. F. (2011). Salamanca Statement and IDEA 2004: Possibilities of Practice for Inclusive Education. International Journal of Inclusive Education, 15(4), 461-476.

Kamariah, Nur \& Mohd, Isa \& Hamzah, \& Hanafi, Mohd \& Yasin, Mohd \& Tahar, Mohd Mokhtar \& Haron, Zolkepeli \& Jasmy, Mohd \& Rahman, Abdul \& Bari, Safani \& Anis, Mohd \& Razak, Abdul \& Samah, Amiruddin. (2019). Teacher's Ability in Identifying Pupils with Disablity in Classroom, KAPIT, SARAWAK.

Mansur, H. (2018, February). Expectations and Challenges the Implementation of Education Inclusive Programs. In First Indonesian Communication Forum of Teacher Training and Education Faculty Leaders International Conference on Education 2017 (ICE 2017). Atlantis Press.

Mansur, H., \& Utama, A. H. (2021). The Evaluation of Appropriate Selection Learning Media at Junior High School. Indonesian Journal of Instructional Media and Model, 3(1), 17-25.

Mansur, H., Utama, A. H., \& Prastitasari, H. (2021). The Problem of Distance Learning During the Covid19 Pandemic. Ilkogretim Online, 20(4).

Mansur, Hamsi, Yasin, Mohd \& Liong, K., (2019). Expectations and Challenges of Implementation Inclusive Education Program: A Case Study. Int. J. Adv. Res. 7(7). 373-379.

Miles, M. B. \& Huberman, A. M. (Rohidi, T. R). (1992), Analisis Data Kualitatif. Jakarta: Universitas Indonesia.

Mohd Rashid, Syar \& Yasin, Mohd \& Ashaari, Noraidah. (2019). Undergraduate Students of Special Education's Readiness towards the Use of Information and Technology (ICT) in Teaching and Learning the Sign Language. Creative Education. 10. 2374-2385. 10.4236/ce.2019.1011169.

Nazir Moh. (2010). Metode Penelitian. Bandung: Ghalia Indonesia.

Omar, Shokhan \& Radzani, Mohd \& Yasin, Mohd \& Dauwed, Mohammed. (2018). Validity and Reliability Questionnaire for Social, Environment and Self-Efficacy Related of Deaf Adolescents Physical Activity. Journal of Theoretical and Applied Information Technology. 96.

Omar, Shokhan \& Yasin, Mohd \& Razak, Mohd \& Dauwed, Mohammed. (2019). Physical Activity Measurement for Hearing Impairments in Different Age Level. 8. 29-35.

Salim, A., \& Utama, A. H. (2020). Evaluasi Sumatif Ketepatan Pemilihan Media Pembelajaran Tepat Guna di Sekolah Dasar (SD) Se-Kota Banjarmasin. Jurnal Penelitian Tindakan dan Pendidikan, 6(2). 
Nama Belakang, Singkatan Nama Depan. (Tahun Publish). Judul Artikel. Edudikara: Jurnal Pendidikan dan Pembelajaran, Vol(Issue), halaman-halaman.

Salim, A., Mansur, H., \& Utama, A. H. (2020). Evaluasi Ketepatan Pemilihan Media Pembelajaran Jarak Jauh di Masa Pandemi Covid-19. Al-Falah: Jurnal Ilmiah Keislaman dan Kemasyarakatan, 20(2), 102116.

Skjorten, M. D. (2001). Towards inclusion and enrichment. Education Special Needs Education: An Introduction. Oslo: Unipub Forlag.

Tessmer, Martin. (1996). Planning and Conducting Formative Evaluation; Improving the Quality of Education and Training. Faculty of Educational Science and Technology, University of Twente, London.

Triwulandari, A., \& Pandia, W. S. S. (2015). Sikap guru terhadap penerapan program inklusif ditinjau dari aspek guru. JPPM (Jurnal Pendidikan dan Pemberdayaan Masyarakat), 2(2), 122-130.

Yasin, Mohd \& Toran, Hasnah \& Tahar, Mohd Mokhtar \& Bari, Safani. (2010). Special Education Classroom Infrastructure: Teacher's Views. Journal Procedia - Social and Behavioral Sciences. 